\title{
Deadbeat Control with a Repetitive Predictor for Three-Level Active Power Filters
}

\author{
Yingjie $\mathrm{He}^{\dagger}$, Jinjun Liu*, Jian Tang**, Zhaoan Wang*, and Yunping Zou** \\ $\dagger^{*}$ School of Electrical Engineering, Xi'an Jiaotong University, Xi'an, China \\ ${ }^{* *}$ School of Electrical and Electronic Engineering, Huazhong University of Science \& Technology, Wuhan, China
}

\begin{abstract}
Three-level NPC inverters have been put into practical use for years especially in high voltage high power grids. This paper researches three-level active power filters (APFs). In this paper a mathematical model in the $d-q$ coordinates is presented for 3 phase 3-wire NPC APFs. The deadbeat control scheme is obtained by using state equations. Canceling the delay of one sampling period and providing the predictive value of the harmonic current is a key problem of the deadbeat control. Based on this deadbeat control, the predictive output current value is obtained by the state observer. The delay of one sampling period is remedied in this digital control system by the state observer. The predictive harmonic command current value is obtained by the repetitive predictor synchronously. The repetitive predictor can achieve a better prediction of the harmonic current with the same sampling frequency, thus improving the overall performance of the system. The experiment results indicate that the steady-state accuracy and the dynamic response are both satisfying when the proposed control scheme is implemented.
\end{abstract}

Key Words: Active power filter, Deadbeat control, Repetitive predictor, State observer, Three-level NPC inverter

\section{INTRODUCTION}

Harmonic pollution is regarded as one of the major problems that degrade electric power quality. Particularly, harmonic resonance in power distribution systems can cause excessive voltage and current waveform distortions with a consecutive instability, abnormal operation and damage to electric components. Passive filters are sensitive to system impedance and load characteristics. The series and parallel resonance problems of this filter are very difficult to solve. The control of harmonic perturbations by active power filters (APFs) has become a hot topic in the power engineering field. In the past two decades, active power filters have developed rapidly to suppress harmonics in the power distribution systems of $380 \mathrm{~V}$ voltage grids[1]-[4]. But the voltage grids of many power distribution systems for making petroleum hole are $600 \mathrm{~V}$. $690 \mathrm{~V}$ voltage grids are widely used in many power distribution systems for mining and wind power. There are many voltage grids ranging from $600 \mathrm{~V}$ to $1000 \mathrm{~V}$ in the factories for steelmaking. Due to the limitations in voltage and current capability of power devices, it is very difficult to handle nonlinear loads in the above mentioned voltage grids for the traditional APFs with a two-level inverter in $380 \mathrm{~V}$ voltage grids. The DC voltage range of traditional APFs in $380 \mathrm{~V}$ voltage grids is

Manuscript received Jan. 19, 2011; revised Apr. 8, 2011

Recommended for publication by Associate Editor Kyo-Beum Lee.

$\dagger$ Corresponding Author: yjhe@mail.xjtu.edu.cn

Tel: +86-28-82668666, Fax: +86-28-82665223, Xi'an Jiaotong Univ.

* School of Electrical Engineering, Xi'an Jiaotong University, China

** School of Electrical and Electronic Engineering, Huazhong University of

Science \& Technology, China usually from $700 \mathrm{~V}$ to $750 \mathrm{~V}$. In these APFs, $1200 \mathrm{~V}$ IGBTs are widely adopted. If traditional APFs with a two-level inverter are adopted in the above mentioned voltage grids, $600 \mathrm{~V}$ voltage grids need a DC voltage of approximately $1125 \mathrm{~V}$ while $690 \mathrm{~V}$ voltage grids needs approximately $1294 \mathrm{~V} .1000 \mathrm{~V}$ voltage grids need a higher DC voltage. Therefore, $1200 \mathrm{~V}$ IGBTs are not suitable for voltage grids and 1700V IGBTs can only be applied to $600 \mathrm{~V}$ voltage grids after a fashion. The switch frequency of $3300 \mathrm{~V}$ IGBTs is comparatively low in the application of an APF and its switch loss is high. At present, the general method is the combining of traditional APFs with a two-level inverter with step-up transformers. However, the transformers are very expensive and occupy up to $40 \%$ of the total system's real estate, which is an excessively large area. Also, their loss is very high and the design of their control system is very difficult due to saturation problems of transformers in the transient state.

In recent years, three-level neutral-point-clamped (NPC) PWM inverters have become an effective and practical solution for many moderate voltage application fields. As described in many papers in the literature, using this technology, the voltage stress on switches will be reduced, the shape of output waveform will be improved and the rate of voltage and power can be increased [5]. Evidently, three-level inverters are very suitable for the harmonic restriction of the voltage grids mentioned above. Adopting this topology, three-level APFs with $1200 \mathrm{~V}$ IGBTs may be used directly in $600 \mathrm{~V}$ and $690 \mathrm{~V}$ voltage grids, and three-level APFs with $1700 \mathrm{~V}$ IGBTs can be applied directly to $1000 \mathrm{~V}$ voltage grids. Moreover, this 
topology can synthesize more output levels which is good for the harmonic current tracking. Furthermore, three-level inverters can be combined with passive filters to form the hybrid filters used in $6.6 \mathrm{kV}$ grids. The hybrid filters can use $1200 \mathrm{~V}$ IGBTs at a reasonable cost from the market[6], [7]. In recent years, APFs with a three-level NPC inverter have been receiving more and more attention [6]-[12].

Obviously, tracking the command current fast and precisely is one of the keys to the design this APF. In recent years, much research on digital feedback control has been carried out on the waveform control of inverters [13]-[21]. Among them the deadbeat control is distinguished by its fast response while providing lower current ripples and a constant switching frequency [13]-[19]. However, when deadbeat control is applied to APFs, there are some new problems to be solved.

Firstly, the command harmonic current compensated by an APF is determined by the load. The command harmonic current is obtained by detecting the load. When the load changes, the command harmonic current changes too. An APF is a servo system. The deadbeat control need know the command current at the coming sampling instant. For an APF, a suitable predictor is required in the design for obtaining the command current at the coming sampling instant. Therefore, predicting the harmonic current at the coming sampling instant precisely is a key problem in the design of the deadbeat control of an APF. Then, the execution of the control program needs time. The calculation of the command voltage should be carried out a sampling period in advanced, otherwise the maximum output pulse width will be significantly reduced. Moreover, the frequency of the harmonic current compensated by the APF is higher than the inverter, the STATCOM and the PWM rectifier. If the delay is not remedied, a delay of one sampling and calculation period in this digital control system will seriously affect the filter effect of this APF. So the delay of one sampling period in this digital control system must be remedied.

A modified deadbeat current regulator with a sampling frequency that is quadruple the switching frequency is presented in the literature [13]. Experimental results are shown to verify the control performance of this current regulator. However, the harmonic current at the coming sampling instant must be predicted to calculate the output voltage of the APF. This paper substitutes the harmonic current value of the coming sampling instant with the value of the current sampling instant. When the frequency of the command harmonic current is very high, the tracking error of this method will change a lot. In the literature [14], a control method was presented which tracks stochastically fluctuating load currents with a dead-beat controller rapidly, and it compensates for the persistent phase error caused by the delay in the dead-beat controller to mitigate the stationary load current harmonics with integrating oscillators. The control method has good steady filtering and dynamic response capabilities. However, the structure of the control method is complicated and only selected stationary harmonics are precisely compensated. When the component of the load current changes, the compensation effect will change a great deal. A deadbeat current regulator with an adaptive predictor was presented in [15]. The feasible validity of the proposed current control algorithm is confirmed by experimental results. However, the delay of one sampling period is remedied by a state predictor based on the controlled system equations using the discretized value. This state predictor is an open loop system. The precision of the state predictor is low. The adaptive predictor for predicting the harmonic current at the coming two sampling instant is based on the harmonic current at the current sampling instant and in the previous fundamental cycle. The structure of this adaptive predictor is complicated and its dynamic response capability is bad for adopting the harmonic current in the previous fundamental cycle.

In order to control the shape of the output current waveform, the paper produces a novel deadbeat control algorithm. Based on the deadbeat control, a predictive output current value is obtained by a state observer adopting the closed loop structure. The delay of one sampling period is remedied accurately by the state observer. A predictive harmonic command current value is obtained by the repetitive predictor synchronously. The repetitive predictor can achieve the function based on the harmonic current at the current sampling instant and on the predicted error in the previous fundamental cycle. The repetitive predictor can achieve better a prediction of the harmonic current with the same sampling frequency, thus improving the overall performance of the system. The experiment results illustrate that the performance of the proposed approach is satisfactory.

\section{Mathematic Model And Control System}

The operating principle of the APF is shown in Fig. 1. The periodic non-sinusoidal current which flows over the nonlinear load (NL) can be resolved into the fundamental current component $i_{l}$ and the summation of all of the harmonic current components $i_{h}$. The reference directions of the currents are defined as shown in Fig.1. $u_{s a}, u_{s b}$ and $u_{s c}$ are the threephase voltages, $i_{c a}, i_{c b}$ and $i_{c c}$ are the currents of the APF, and $i_{l a}, i_{l b}$ and $i_{l c}$ are the nonlinear load currents. After the load currents flow through the current transformers, the desired currents which the APF should compensate are first obtained by the detecting circuit of the harmonic currents. Then the desired currents are injected into the power system by the APF controlling the PWM inverter. It can be seen from Fig.1 that source current $i_{s}$ is provided with both the load current $i_{l}$ and the output current $i_{c}$ of the APF, i.e., $i_{s}=i_{l}+i_{c}$. Since $i_{c}=-i_{h}$, the power source only supplies $i_{l}$. Hence $i_{s}$, after compensation, becomes a sinusoidal current which has a frequency that is identical to $u_{s}$. This is the basic operating principle of the APF.

The three-level NPC inverter applied to the APFs, as shown in Fig. 1, is built-up of twelve switches, each with a freewheeling diode, and six power diodes which allow for the connection of the phase outputs to the middle voltage. From Fig. 1, it can be seen that each phase of the NPC three-level inverter consists of four switches. The blocking voltage of each switch is $1 / 2$ of the DC voltage. Each arm of the inverter can be clamped to the DC terminals $\mathrm{P}, \mathrm{N}$ and $\mathrm{Q}$, to produce three switching states. When the upper two switches $T_{1}$ and $T_{2}$ are switched on, the output of this phase is connected to 


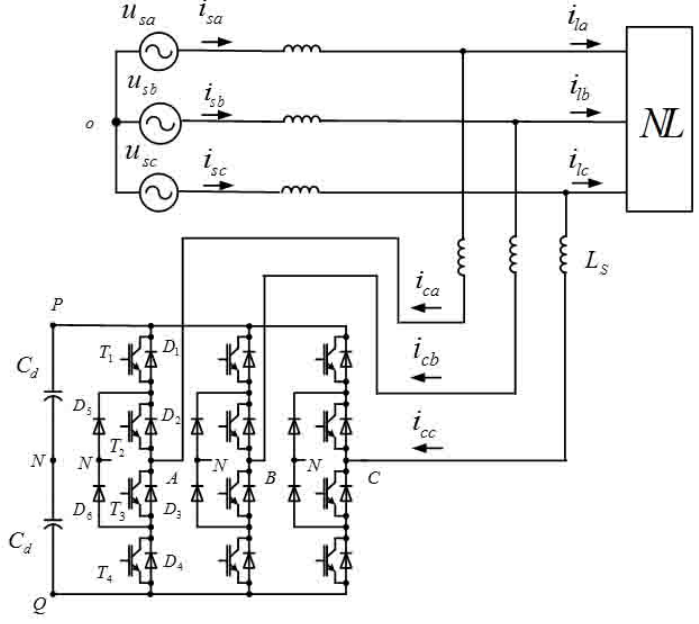

Fig. 1. Schematic diagram of the active power filter with three-level inverter.

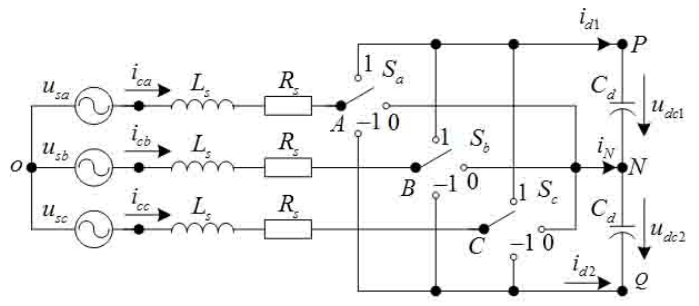

Fig. 2. The equivalent circuit of the active power filter with three-level inverter.

the DC terminal P. When the middle two switches $T_{2}$ and $T_{3}$ are switched on, the output of this phase is connected to the middle point N. Similarly when the lower two switches $T_{3}$ and $T_{4}$ are switched on, the output of this phase is connected to $\mathrm{Q}$. The allowed logic configurations of the NPC switches are able to provide the three different output voltage values furnished by each NPC inverter phase. The states of $T_{1}, T_{2}, T_{3}$ and $T_{4}$ are complementary. The two switches for each phase of the NPC inverter are closed, whilst the other two are opened at every time instant [5].

In this paper, the losses of the switching devices and the snubber circuits are ignored. Based on the concept of the switching function (SF), an equivalent switch-circuit of a three-level NPC APF can be obtained as Fig. 2. The power loss on the resistor R is assumed to include all filter's losses. The three phase source voltage is assumed to be balanced and symmetrical. The switching state of phase A, $S_{a}$ for the power devices $T_{1 a}-T_{4 a}$, is defined as:

$$
S_{a}= \begin{cases}1, & T_{1 a}, T_{2 a} \text { ON and } T_{3 a}, T_{4 a} \text { OFF } \\ 0, & T_{2 a}, T_{3 a} \text { ON and } T_{1 a}, T_{4 a} \text { OFF } \\ -1, & T_{3 a}, T_{4 a} \text { ON and } T_{1 a}, T_{2 a} \text { OFF }\end{cases}
$$

The switch states are coded by the symbols $-1,0$ and 1 identifying the three voltage levels on each inverter phase. To get the mathematic model of the APF, $S_{a}$ is decomposed as:

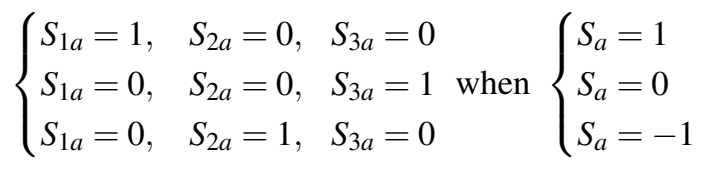

Using the same method, $S_{b}$ and $S_{c}$ are decomposed. Then, a comprehensive mathematic model of the three-level inverter in the stator coordinates is established as follows:

$$
Z \dot{X}=A \cdot X+B \cdot e
$$

where:

$$
\begin{gathered}
Z=\operatorname{diag}\left[\begin{array}{lllll}
L_{s} & L_{s} & L_{s} & C_{d} & C_{d}
\end{array}\right] \\
X=\left[\begin{array}{lllll}
i_{c a} & i_{c b} & i_{c c} & u_{d c 1} & u_{d c 2}
\end{array}\right]^{T} \\
A=\left[\begin{array}{cccccc}
-R_{s} & 0 & 0 & -S_{1 a}+\frac{S_{1 a}+S_{1 b}+S_{1 c}}{3} & S_{2 a}-\frac{S_{2 a}+S_{2 b}+S_{2 c}}{3 b} \\
0 & -R_{s} & 0 & -S_{1 b}+\frac{S_{1 a}+S_{1 b}+S_{1 c}}{S_{1 a}} & S_{2 b}-\frac{S_{2 a}+S_{2 b}+S_{2 c}}{3}+S_{1 c} & S_{2 c}-\frac{S_{2 a}+S_{2 b}+S_{2 c}}{3} \\
0 & 0 & -R_{s} & -S_{1 c}+\frac{S_{1}}{3} & 0 & 0 \\
S_{1 a} & S_{1 b} & S_{1 c} & 0 & \\
-S_{2 a} & -S_{2 b} & -S_{2 c} & 0 & 0
\end{array}\right] \\
B=\operatorname{diag}\left[\begin{array}{llllll}
1 & 1 & 1 & 0 & 0 & ]
\end{array}\right] \\
e=\left[\begin{array}{llllll}
u_{s a} & u_{s b} & u_{s c} & 0 & 0 & ]^{T}
\end{array}\right.
\end{gathered}
$$

To simplify the mathematic model, the synchronous rotating coordinate transformation is used. A mathematical model of the tri-level system in the rotating $d q$ frame is expressed as follows:

$$
Z \dot{X}=A \cdot X+B \cdot e
$$

where:

$$
\begin{gathered}
Z=\operatorname{diag}\left[\begin{array}{llll}
L_{s} & L_{s} & C_{d} & C_{d}
\end{array}\right] \\
X=\left[\begin{array}{llll}
i_{c d} & i_{c q} & u_{d c 1} & u_{d c 2}
\end{array}\right]^{T} \\
A=\left[\begin{array}{cccc}
-R_{s} & \omega L_{s} & -S_{d 1} & S_{d 2} \\
-\omega L_{s} & -R_{s} & -S_{q 1} & S_{q 2} \\
S_{d 1} & S_{q 1} & 0 & 0 \\
-S_{d 2} & -S_{q 2} & 0 & 0
\end{array}\right] \\
B=\operatorname{diag}\left[\begin{array}{llll}
1 & 1 & 0 & 0
\end{array}\right] \\
e=\left[\begin{array}{llll}
u_{s d} & u_{s q} & 0 & 0
\end{array}\right]
\end{gathered}
$$

By this means, the three-phase alternating signal is changed into a two-phase alternating signal. Thus the mathematic model of this APF is predigested. Base on the mathematic model, the control system of the APF is designed. A diagram of the control system is shown in Fig. 3. The control system includes an outer-loop voltage controller and an inner-loop current controller. The outer-loop controller is used to produce the command active current to regulate the $\mathrm{DC}$ voltage. The inner-loop current controller is divided into the detection module for calculating the harmonic current and the control module for tracking the command current and restraining the neutral-point voltage imbalance. The method for detecting the harmonic currents, based on the instantaneous reactive power theory, is adopted in the detection module [1]. The control module for tracking the command current deals with shaping the current waveforms to track the references. The command current of the control module is composed of a DC voltage regulator component and a harmonic current compensator component. In order to control the shape of the output current waveform, a novel deadbeat control technology is presented. The neutral-point voltage imbalance is restrained by selecting the small vectors that will move the neutral-point voltage in the direction opposite the direction of the unbalance from the space vector PWM point of view in the control module [22]. 


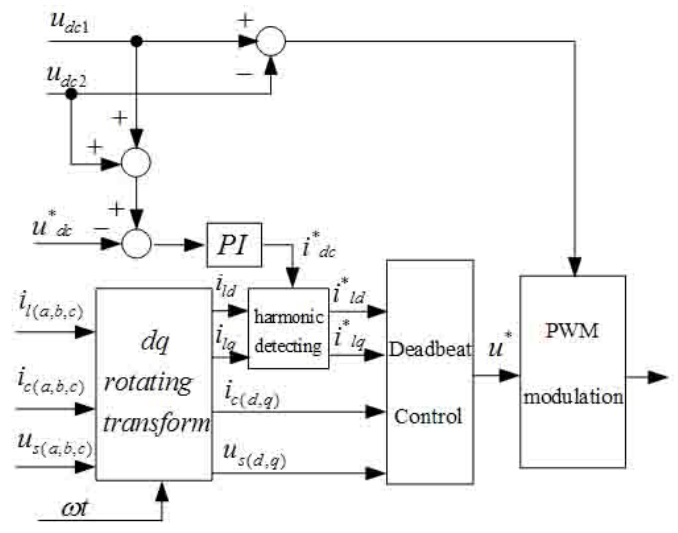

Fig. 3. Block diagram of control system of the active power filter with threelevel inverter.

\section{Novel Deadbeat Control Method}

Generally, deadbeat control is a digital feedback strategy designed to control the pulse width so that the output of the converter can track the reference at every sampling instant[1519]. Any deviation from the reference due to a load disturbance is corrected in one sampling interval $T_{s}$. The switching instant value is determined through calculating the required voltage to force the output currents to follow the references. In the $d q$ two-phase rotating coordinate, the expressions of deadbeat control is given by:

$$
\begin{gathered}
\dot{X}=A \cdot X+B \cdot U \\
X=\left[\begin{array}{ll}
i_{c d} & i_{c q}
\end{array}\right]^{T} \\
U=\left[\begin{array}{ll}
u_{s d}-u_{d} & u_{s q}-u_{q}
\end{array}\right]^{T} \\
A=\left[\begin{array}{cc}
-\frac{R_{s}}{L_{s}} & \omega \\
\omega & -\frac{R_{s}}{L_{s}}
\end{array}\right] \\
B=\left[\begin{array}{cc}
\frac{1}{L_{s}} & 0 \\
0 & \frac{1}{L_{s}}
\end{array}\right]
\end{gathered}
$$

Then the sample data model becomes as follows:

$$
\begin{gathered}
X(k+1)=G \cdot X(k)+H \cdot U(k) \\
X(k)=\left[\begin{array}{ll}
i_{c d}(k) & i_{c q}(k)
\end{array}\right]^{T} \\
U(k)=\left[\begin{array}{cl}
u_{s d}(k)-u_{d}(k) & u_{s q}(k)-u_{q}(k)
\end{array}\right]^{T} \\
G=e^{A \cdot T_{s}} \\
H=\left(e^{A \cdot T},-I\right) \cdot A^{-1} \cdot B
\end{gathered}
$$

Thus, the command voltage of deadbeat control is given from formula (6):

$$
\begin{aligned}
& {\left[\begin{array}{l}
u_{d}(k) \\
u_{q}(k)
\end{array}\right]=H^{-1} \cdot G \cdot\left[\begin{array}{l}
i_{c d}(k) \\
i_{c q}(k)
\end{array}\right]} \\
& -H^{-1} \cdot\left[\begin{array}{l}
i_{c d}(k+1) \\
i_{c q}(k+1)
\end{array}\right]+\left[\begin{array}{l}
u_{s d}(k) \\
u_{s q}(k)
\end{array}\right] .
\end{aligned}
$$

Based on the sampling value of the output current $i_{c}(k)$, the sampling value of the power voltage $u_{s}(k)$, the command value of the load harmonic current $i_{h}(k+1)$, and the command voltage can be calculated from the above formula. This means that the command voltage is a linear combination of the two state variables and the two inputs in the deadbeat control. In the deadbeat control, the pole of the control system is placed at zero. In the steady process, the output current accurately tracks the command current at every sampling instant[19].

Evidently, predicting harmonic current at the coming sampling instant precisely is a key problem in designing this deadbeat control from formula (7). If the harmonic current at the coming sampling instant can not be predicted, the harmonic current value of the coming sampling instant $i_{h}(k+1)$ in formula (7) is substituted with the value of the current sampling instant $i_{h}(k)$. Then the effect of the deadbeat control becomes as follows:

$$
i_{c}(k+1)=i_{c}^{*}(k) .
$$

So by doing that, the output current lags the command current by one sampling period. Because the frequency of the harmonic current compensated by the APF is higher than the power fundamental frequency, $i_{h}(k+1)$ can be enormously different from $i_{h}(k)$. As a result, the tracking error is very serious. When the harmonic command current chops, the tracking error is biggest and the compensation effect of the APF will be very bad.

Since the execution of the control program needs time, the calculation of the command voltage should be carried out a sampling period in advanced, otherwise the maximum output pulse width will be significantly reduced. The calculation of the command voltage is carried out during the above sampling period. That is to say, the command voltage calculated in the $(k)^{\text {th }}$ sampling period is carried out during the $(k+1)^{\text {th }}$ sampling period, there is a delay of one sampling period. In the condition, formula (7) changes as follows:

$\left[\begin{array}{l}u_{d}(k) \\ u_{q}(k)\end{array}\right]=H^{-1} \cdot G \cdot\left[\begin{array}{l}i_{c d}(k-1) \\ i_{c q}(k-1)\end{array}\right]-H^{-1} \cdot\left[\begin{array}{l}i_{c d}^{*}(k) \\ i_{c q}^{*}(k)\end{array}\right]+\left[\begin{array}{l}u_{s d}(k-1) \\ u_{s q}(k-1)\end{array}\right]$.

The command value obtained from formula (9) is substituted into formula (6) then the model with a delay of one sampling period is given as follows:

$$
\left[\begin{array}{c}
i_{c d}(k+1) \\
i_{c q}(k+1)
\end{array}\right]=G \cdot\left[\begin{array}{c}
i_{c d}(k)-i_{c d}(k-1) \\
i_{c q}(k)-i_{c q}(k-1)
\end{array}\right]+\left[\begin{array}{c}
i_{c d}^{*}(k) \\
i_{c q}^{*}(k)
\end{array}\right] .
$$

Evidently, the output current can not track the command current with no misadjustment in a system with a delay of one sampling period. Because the matrix $\mathrm{G}$ is approximately equal to the unit matrix (the system parameters adopted are consistent with those of the experiment below), the tracking error is given by:

$$
\begin{aligned}
& {\left[\begin{array}{l}
e_{c d}(k+1) \\
e_{c q}(k+1)
\end{array}\right]=\left[\begin{array}{c}
i_{c d}(k+1)-i_{c d}^{*}(k+1) \\
i_{c q}(k+1)-i_{c d}^{*}(k+1)
\end{array}\right]} \\
& =\left[\begin{array}{c}
i_{c d}(k)-i_{c d}(k-1) \\
i_{c q}(k)-i_{c q}(k-1)
\end{array}\right]-\left[\begin{array}{c}
i_{c d}^{*}(k+1)-i_{c d}^{*}(k) \\
i_{c q}^{*}(k+1)-i_{c q}^{*}(k)
\end{array}\right] .
\end{aligned}
$$

Because the frequency of the harmonic current compensated by the APF is very high, the difference between $i_{c}(k)-i_{c}(k-$ $1)$ and $i_{c}(k+1)-i_{c}(k)$ is very large. As a result, the output current can not track the command current and the tracking error is very large from formula (11). When the harmonic 


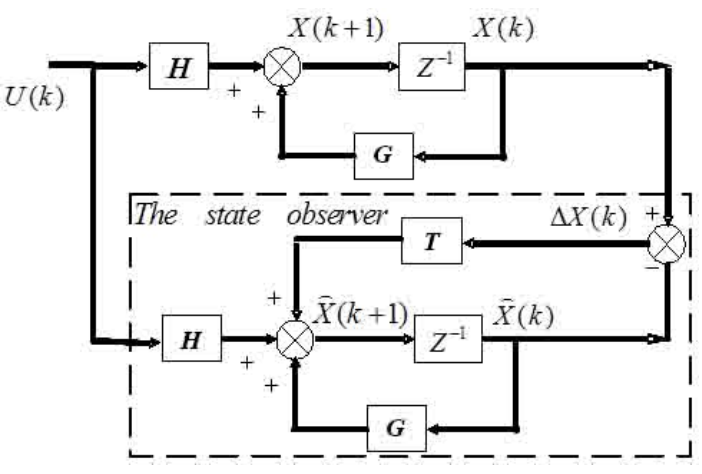

Fig. 4. The state observer.

current being compensated chops, likewise the compensation effect of the APF will be very bad. Therefore, the delay of one sampling period in this digital control system must be remedied.

Based on the above paragraph, predicting the harmonic currents at the coming sampling instant precisely and remedying the delay of one sampling period are the two key problems in designing this APF. The control process should be like this: at the $(k-1)$ thinstant, sample the output current $i_{c}(k$ 1) of the APF, then estimate $i_{c}(\mathrm{k})$. Meanwhile sample the load current $i_{l}(\mathrm{k}-1)$, calculate the harmonic current $i_{h}(\mathrm{k}-1)$, and then predict $i_{h}(\mathrm{k}+1)$. Finally the desired voltages are determined with formula (7).

Based on the structure of the APF, a good solution for the estimation of APF output currents is a state observer. A full order state observer for this APF is designed based on formula (6) as follows:

$$
\widehat{X}(k+1)=G \cdot \widehat{X}(k)+H \cdot U(k)+T(X(k)-\widehat{X}(k))
$$

The state observer is shown in fig. 4 . In this figure $\widehat{X}(k)$ and $\widehat{X}(k+1)$ denote the estimated values of the output currents at the $k t h$ and $(k+1) t h$ sampling instants. The principle of the state observer is using the parameters of the controlled system to build a state observer system. The estimated values of $\widehat{X}(k)$, calculated by the state observer system, are taken for the actual values of $X(k)$ for the controlled system. The state observer is a closed loop structure and $T$ is the observer feedback gain. In order to overcome the original observer error and the modeling error of the state observer, the observer error is revised by the difference of the estimated value and the actual value through the observer feedback gain $T$. Finally the revised observer error is from (6) and (12) as follows:

$$
e_{x}(k+1)=(G-T) \cdot e_{x}(k)
$$

where $e_{x}(k)=X(k)-\overparen{X}(k)$ is the observer error. The poles of the observer matrix (G-T) can be arbitrarily placed by adjusting the feedback gain $T$. Theoretically, this observer may give zero steady errors. In practice it is easy to make the observer error close to zero and the observer stability very good by setting the poles of the observer matrix suitably.

It seems impossible to model the load current disturbance precisely when considering the diversity of load types. Since harmonics are repetitive most of the time, it makes sense to adopt a repetitive algorithm to predict the seemingly

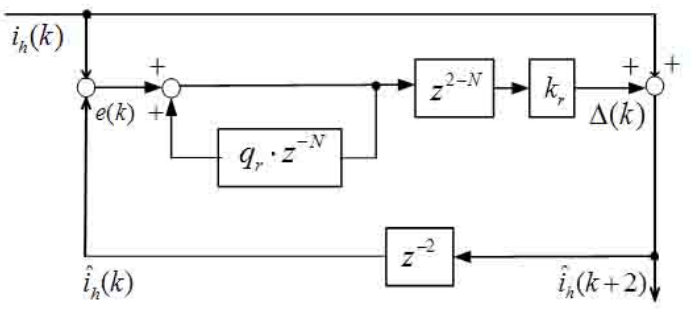

Fig. 5. The repetitive predictor.

unpredictable load currents. The basic theorem of repetitive harmonic predictor is shown in Fig. 5.

The algorithm can be viewed as a plug-in repetitive compensator for a basic predictor. The basic predictor is a two unit delay: $z^{-2}$, which means that it just takes the value of the harmonic current at the kth sampling instants (namely $i_{h d}(\mathrm{k})$ and $\left.i_{h q}(\mathrm{k})\right)$ for the estimated value of the harmonic current at the $(k+2)$ th sampling instant since the $(k+2)$ th sampling process has not yet begun. The input of the compensator is $e$, which is defined as the difference between the value of the actual current and the estimated value. It is assumed that the harmonic current is sampled $N$ times in a fundamental cycle. Sampling exactly $N$ times in a fundamental cycle is easy to achieve with the phase locked loop of active power filters [23]. In order to repetitively compensate the error of basic predictions, $N$ memory cells are prepared to store the correction values (namely $\Delta(k), k \in[1, N]$ ) in one fundamental cycle. The predicted value of the harmonic current at the $(k+2)$ th sampling instant (namely $\hat{i}_{h}(k+2)$ ) can be obtained by adding $\Delta(k)$ to the value of the harmonic current at the $k t h$ sampling instant, as in formula (14). The correction value $\Delta(k)$ for correcting the basic prediction value $i_{h}(k)$ to predict $\hat{i}_{h}(k+2)$ is modified periodically by adding the prediction error to the current correction value $\Delta(k)$. The prediction error is obtained by subtracting the predicted value of the harmonic current $\hat{i}_{h}(k)$ from the actual harmonic current value $i_{h}(k)$. Evidently, the dynamic response of this method is faster than the dynamic response of the method of adopting the harmonic command current value from the former fundamental cycle as the predicted value.

$$
\hat{i}_{h}(k+2)=i_{h}(k)+\Delta(k) .
$$

In a physical system, the harmonic waveform in the next fundamental cycle can not identically replicate the waveform in the current fundamental cycle even if the load is in the steady state on account of an affection of all kinds of disturbances. Therefore, as shown in Fig. 5, the repetitive predictor adopts the modified internal model $1 /\left(1-q_{r} z^{-N}\right)$. $q_{r}$ may be a low pass filter or a constant less than 1. In this way, the "pure integral" structure can be changed into a "quasiintegral" form, avoiding the $N$ open loop poles situated on the unit circle circumference caused by pure integral so as to make the open loop system not join in the critical oscillation state. In the case of unperfected modeling, $q_{r}$ can improve the stability of the predictor system by eliminating the error $e$ by half. The period delay part $z^{-N}$ in the forward channel make the predictor action delayed by one fundamental period, i.e. the error information examined in this period will affect 


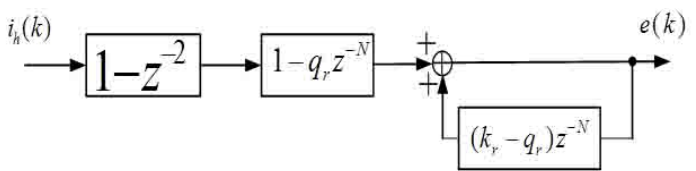

Fig. 6. The equivalent structure of the prediction error.

the predictor quantity in the next period. Since it has been supposed that the references are all repetitive, the system's predictor effect in next period will be made to have a certain leading in this way. $k_{r}$ is the gain of the repetitive predictor. A proper $k_{r}$ was designed to compromise the stability margin for the error convergence time. The time advance unit $z^{2}$ was used to predict the harmonic current two sampling cycles in advanced.

From Fig. 5, the transfer function of the prediction error is as follows:

$$
e(z)=i_{h}(z) \frac{\left(1-z^{-2}\right)\left(1-q_{r} z^{-N}\right)}{1-q_{r} z^{-N}+k_{r} z^{-N}} .
$$

From (15), the equivalent block diagram of the transfer function of the prediction error is shown as follows:

According to the small gain theorem: if the open-loop gain of a feedback loop system is always less than 1, the system is stable. Therefore, from Fig. 6, the sufficient condition for keeping the repetitive harmonic predictor stable is obtained as follows:

$$
\left|q_{r}\left(e^{j \omega T_{s}}\right)-k_{r}\left(e^{j \omega T_{s}}\right)\right|<1, \omega \in\left[0, \pi / T_{s}\right] .
$$

In which: $z$ is replaced in formula (15) with $e^{j \omega T_{s}}$. Formula (16) means: while $\omega$ varies from a zero frequency to the nyquist frequency, if (16) is satisfied, then the repetitive predictor is sufficiently stable. $k_{r}$ and $q_{r}$ may be a filter or a constant. Choosing the two parameters $k_{r}$ and $q_{r}$ to be constant is proven to be suitable and easy to design with large numbers of simulation results. If $k_{r}$ and $q_{r}$ are constant, formula (16) is simplified as:

$$
\left|q_{r}-k_{r}\right|<1 .
$$

Therefore, the two parameters $k_{r}$ and $q_{r}$ may be designed with formula (16) to guarantee stabilization of the repetitive predictor. Based on formula (15), the prediction error after one fundamental cycle is given as:

$$
z^{N} e(z)=\left(1-z^{-2}\right)\left(z^{N}-q_{r}\right) i_{h}(z)+\left(q_{r}-k_{r}\right) e(z) .
$$

Assuming the harmonic current reference to be purely repetitive and $q_{r}$ to be approximately equal to 1 , we get:

$$
z^{N} e(z)=\left(q_{r}-k_{r}\right) e(z) .
$$

Formula (19) means that the error will be reduced by $\left(q_{r}-\right.$ $\left.k_{r}\right)$ after each fundamental cycle. Therefore, when $\left(q_{r}-k_{r}\right)$ is smaller, the convergence speed of tracking error is faster.

From formula (15), the magnitude of the steady-state tracking error of the reference is determined by:

$$
\left|e\left(e^{j \omega T_{s}}\right)\right|=\left|\frac{1-q_{r}}{1-\left(q_{r}-k_{r}\right)}\right|\left|\left(1-e^{-j 2 \omega T_{s}}\right) i_{h}\left(e^{j \omega T_{s}}\right)\right| .
$$

In the steady-state, the reference tracking error is reduced to $\left|\left(1-q_{r}\right) /\left(1-q_{r}+k_{r}\right)\right|$ times the original value. Therefore,

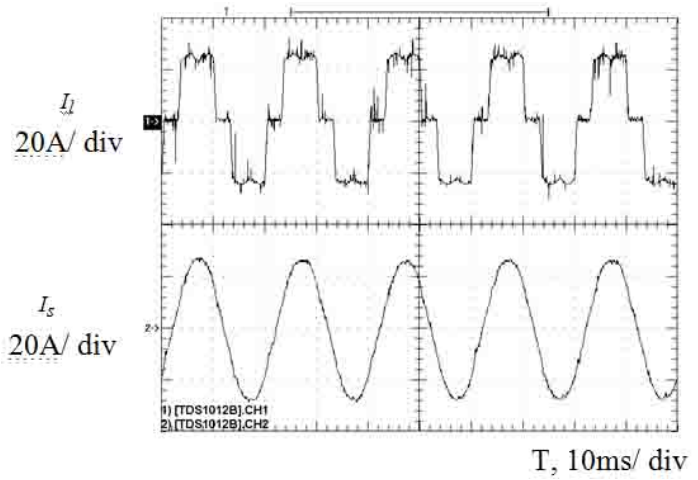

Fig. 7. Experimental steady waveforms of load current and system supply current.

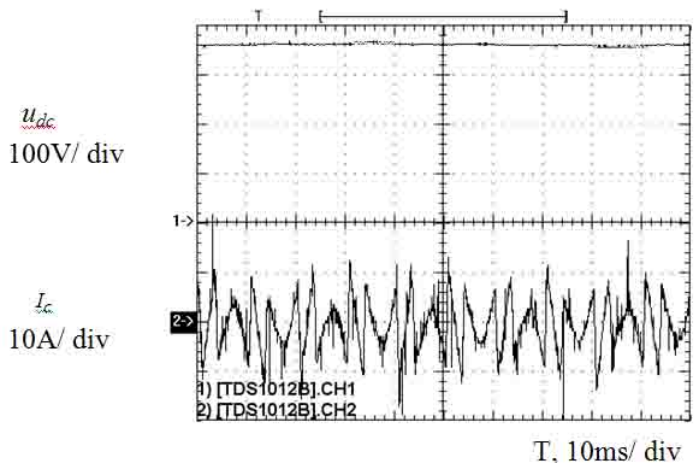

Fig. 8. Experimental steady waveform of DC voltage and APF output current.

if $\left|\left(1-q_{r}\right) /\left(1-q_{r}+k_{r}\right)\right|$ is smaller, the tracking error in the steady-state is smaller. In practice, the load current does not exactly repeat itself from cycle to cycle. Based on the abovementioned analysis, for guaranteeing the stability and the dynamic steady characteristic of the predictor system, $k_{r}$ is chosen as 0.98 and $q_{r}$ is chosen as 0.95 .

\section{EXPERIMENT RESULT}

Theoretic analysis results are necessary to further verify the actual circuits. A diagrammatic sketch of the experiment power circuits is shown in Fig. 1. The parameters of the circuit and the control system model for the experiment are listed in Table I. All of the control algorithms are implemented with a TMS320F2407 DSP. The nonlinear load is a threephase bridge rectifier with an inductance and a resistance. The source voltage is $u_{s}=110 \mathrm{~V} / 50 \mathrm{H}$, and the impedance of voltage source is $L_{S}=1 \mathrm{mH}$. A 2SK1020 P-MOSFET is selected as the switching device. Some important experimental oscillograms are shown respectively as follows:

Fig. 7 shows experimental steady waveforms of the load current and the system supply current, where waveform 1 is the load current $i_{l}$ and waveform 2 is the system supply current $i_{s}$ through the APF filtering. The THD (total harmonic distortion) of the load current $i_{l}$ is calculated to be $22.54 \%$. The THD of $i_{s}$ is $2.73 \%$. Fig.7 proves that the proposed APF has good steady filtering capability. Fig.8 shows the experimental steady waveforms of the DC voltage and the APF output current, where waveform 1 is the DC voltage and waveform 2 is the APF output current through the APF filtering. As shown in Fig.8, the DC capacitor voltages are regulated to fluctuate in a 


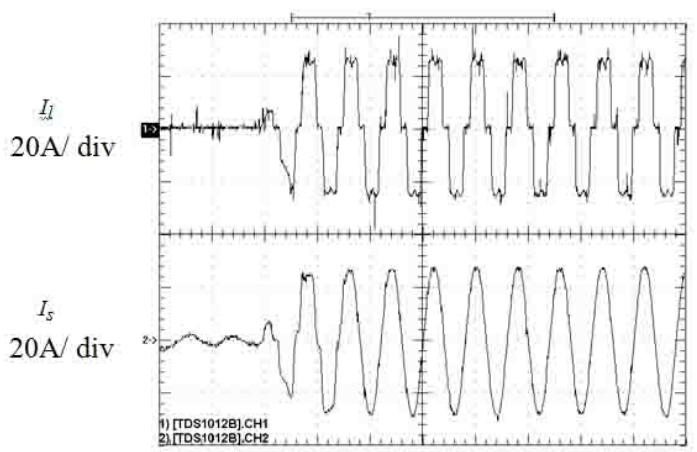

T, $25 \mathrm{~ms} / \mathrm{div}$

Fig. 9. Experimental dynamic waveforms of load current and system supply current when nonlinear load is added.

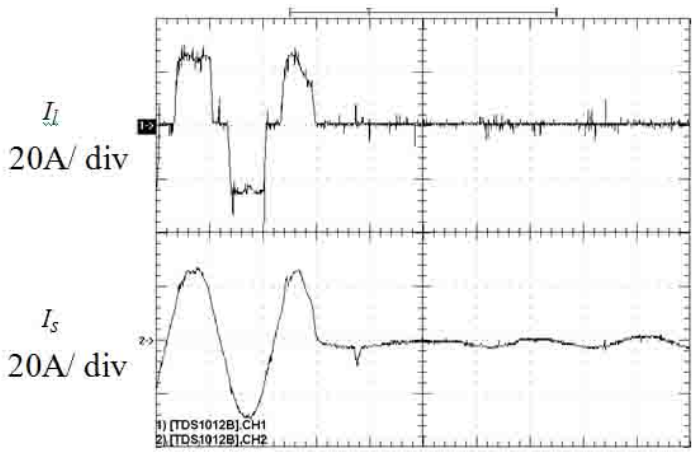

$\mathrm{T}, 10 \mathrm{~ms} / \mathrm{div}$

Fig. 10. Experimental dynamic waveforms of load current and system supply current when nonlinear load is removed.

small range near the reference voltage $360 \mathrm{~V}$ during the APF steady operation.

Fig. 9 presents the dynamic experimental waveforms when a nonlinear load is added abruptly, where waveform 1 is the load current $i_{l}$ and waveform 2 is the system supply current $i_{s}$ through the APF filtering. Fig. 10 shows the dynamic experimental waveforms when a nonlinear load is removed abruptly, where waveform 1 is the load current $i_{l}$ and waveform 2 is the system supply current $i_{s}$. Fig. 9 and Fig. 10 prove that the proposed APF has a good dynamic response under load adding and removing processes. It is obvious that the proposed APF is controlled very well by the novel deadbeat control. The experimental waveforms of $u_{A N}$ and $u_{A B}$ are illustrated in Fig. 11, where waveform 1 is $u_{A N}$ and waveform 2 is $u_{A B}$. It is obvious that the output voltage $u_{A N}$ furnished by each NPC inverter phase is three-level and that the line-line output voltage $u_{A B}$ is five-level. Fig. 11 shows that the proposed APF is fit for application in voltage grids ranging from $600 \mathrm{~V}$ to $1000 \mathrm{~V}$

\section{CONClusions}

This paper investigates the control problems for active power filters with a three-level NPC inverter and proposes a novel deadbeat control algorithm for tracking harmonic command currents. In this scheme, the state variables are estimated by a state observer to cancel the delay of one sampling period in the digital control system. The harmonic current is predicted with a repetitive algorithm simultaneity, which makes use of the repetitive nature of the load current. The

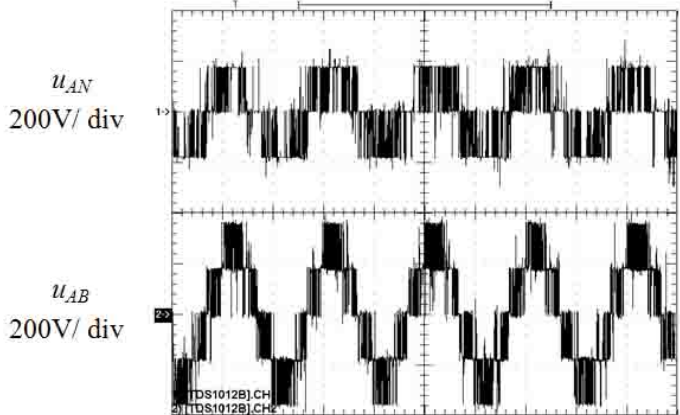

$\mathrm{T}, 10 \mathrm{~ms} / \operatorname{div}$

Fig. 11. Experimental waveforms of $u_{A N}$ and $u_{A B}$.

TABLE I

THE PARAMETERS OF THE CIRCUIT AND CONTROL SYSTEM

\begin{tabular}{|c|c|l|}
\hline Symbol & Experiment & \multicolumn{1}{c|}{ Explanation } \\
\hline$U_{s}$ & $110 \mathrm{~V}$ & the RMS phase voltage value \\
\hline$f$ & $50 \mathrm{~Hz}$ & Power frequency \\
\hline$L_{s}$ & $2 \mathrm{mH}$ & the filter inductance \\
\hline$u_{d c}$ & $360 \mathrm{~V}$ & DC voltage of the filter \\
\hline$C_{d}$ & $4700 \mu \mathrm{F}$ & DC capacitor of the filter \\
\hline$f_{s}$ & $9.6 \mathrm{kHz}$ & sampling $\backslash$ switch frequency \\
\hline$k_{p}$ & 1.6 & DC controller parameter $k_{p}$ \\
\hline$k_{I}$ & 64 & DC controller parameter $k_{I}$ \\
\hline$k_{r}$ & 0.98 & repetitive predictor parameter $k_{r}$ \\
\hline
\end{tabular}

experimental results illustrate that this APF can be controlled in a satisfactory way.

\section{ACKNOWLEDGMENT}

This work was supported by National Science Foundation of China (No.50907052), and with grants from the Power Electronics Science and Education Development Program of the Delta Environmental and Educational Foundation.

\section{REFERENCES}

[1] H. Akagi, Y. Kanazawa, and A. Nabae, "Instantaneous reactive power compensators comprising switching devices without energy storage components," IEEE Trans. Ind. Appl., Vol. 20, No. 2, pp. 625-630, May 1984.

[2] E. Lavopa, P. Zanchetta, M. Sumner, and F. Cupertino, "Real-time estimation of fundamental frequency and harmonics for active shunt power filters in aircraft electrical systems," IEEE Trans. Ind. Electron., Vol. 58, No. 8, pp. 2875-2884, Aug. 2009.

[3] R. Grino, R. Cardoner, R. Costa-Castello, and E. Fossas, "Digital repetitive control of a three-phase four-wire shunt active filter," IEEE Trans. Ind. Electron., Vol. 54, No. 3, pp. 1495-1503, Jun. 2007.

[4] V. F. Corasaniti, M. B. Barbieri, P. L. Arnera, and M. I. Valla, "Hybrid power filter to enhance power quality in a medium-voltage distribution network," IEEE Trans. Ind. Electron., Vol. 56, No. 8, pp. 2885-2893, Aug. 2009.

[5] N. Akira, I. Takahashi, and H. Akagi, "A new neutral-point-clamped PWM inverter,' IEEE Trans. Ind. Appl., Vol. 17, No. 3, pp. 518-523, Sep. 1981.

[6] H. Akagi, R. Kondo, "A transformerless hybrid active filter using a three-level PWM converter for a medium-voltage motor drive," in Proc. ECCE, pp. 1732-1739, 2009.

[7] H. Akagi, T. Hatada, "Voltage balancing control for a three-level diodeclamped converter in a medium-voltage transformerless hybrid active filter,' IEEE Trans. Power Electron., Vol. 24, No. 3, pp. 571-579, Mar. 2009.

[8] H. Rudnick, J. Dixon, and L. Moran, "Delivering clean and pure power," IEEE Power and Energy Magazine, Vol. 1, No. 5, pp. 32-40, Sep. 2003.

[9] M. C. Wong, J. Tang, and Y. D. Han, "Cylindrical coordinate control of 3-D PWM technology in 3-phase 4-wire tri-level inverter," IEEE Trans. Power Electron., Vol. 18, No. 1, pp. 208-220, Jan. 2003. 
[10] N. Y. Dai, M. C. Wong, and Y. D. Han, "Application of a three-level NPC inverter as a three-phase four-wire power quality compensator by generalized 3DSVM," IEEE Trans, Power Electron., Vol. 21, No. 2, pp. 51-58, Mar. 2006

[11] M. Basu, S. P. Das, and G. K. Dubey, "Parallel converter scheme for high-power active power filters," in Proc. IEE Electric Power Applications, Vol. 151, No. 4, pp. 460-466, Jul. 2004.

[12] O. Vodyakho, C.C. Mi, "Three-level inverter-based shunt active power filter in three-phase three-wire and four-wire systems," IEEE Trans. Power Electron., Vol. 24 No. 5, pp. 1350-1363, May.2009.

[13] H. Fujita, "A single-phase active filter using an H-bridge PWM converter with a sampling frequency quadruple of the switching frequency," IEEE Trans. Power Electron., Vol. 24, No. 4, pp. 934-941, Jun. 2009.

[14] J. Allmeling, "A control structure for fast harmonics compensation in active filters," IEEE Trans. Power Electron., Vol. 19, No. 2, pp. 508-514, Mar. 2004.

[15] K. Nishida, M. Nakaoka, "Deadbeat current control with adaptive predictor for three-phase voltage-source active power filter," in Proc. PESC, pp. 1010-1016, 2004.

[16] K. Nishida, M. Rukonuzzaman, and M. Nakaoka, "Digital control threephase shunt active power filter with a new harmonic-current-extraction process," in Proc. IEE Generation, Transmission and Distribution, Vol. 152, No. 4, pp. 529-538, Jul. 2005.

[17] Y. A.-R. I. Mohamed, E. F. El-Saadany, "An improved deadbeat current control scheme with a novel adaptive self-tuning load model for a threephase PWM voltage-source inverter," IEEE Trans. Ind. Electron., Vol. 54, No. 2, pp. 747-759, Apr. 2007.

[18] P. Mattavelli, "An improved deadbeat control for UPS using disturbance observers," IEEE Trans. on Ind. Electron., Vol. 52, No. 1, pp. 206-212, Feb. 2005 .

[19] K. Zhang, Y. Kang, J. Xiong, and J. Chen, "Deadbeat control of PWM inverter with repetitive disturbance prediction," in Proc. APEC, pp. 10261031, 1999.

[20] O. Vodyakho, D. Hackstein, A. Steimel, and K. Taehyung, "Novel direct current-space-vector control for shunt active power filters based on the three-level inverter," IEEE Trans. Power Electron., Vol. 23, No. 4, pp. 1668-1678, Jul. 2008

[21] C. Lascu, L. Asiminoaei, I. Boldea, and F. Blaabjerg, "Frequency response analysis of current controllers for selective harmonic compensation in active power filters," IEEE Trans. Ind. Electron., Vol. 56, No. 2, pp. 337-347, Feb. 2009.

[22] N. Celanovic and D. Voroyevich, "A comprehensive study of neutralpoint voltage balancing problem in three-level neutral-point-clamped voltage source PWM inverters," IEEE Trans. on Power Electron., Vol. 15, No. 2, pp. 242-249, Mar. 2000.

[23] L. Wu, F. Zhuo, and Z. Wang, "Soft phase locked loop for active power filter applied in small rating stand-alone power system," in Proc. PESC, pp. 2600-2606, 2007.

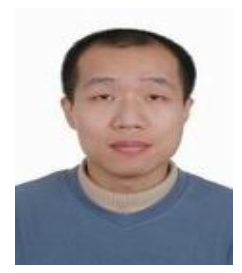

Yingjie He was born in Henan Province, China in 1978. He received his B.S, M.S. and Ph.D. from the Huazhong University of Science and Technology, China in 1999, 2003 and 2007, respectively. From May 2007 until May 2009, he was with the Power Electronics and Renewable Energy Center at Xi'an Jiaotong University, China, as a Postdoctoral Research Scholar. He is currently a Lecturer at Xi' an Jiaotong University. His research interests include power quality control, multilevel inverters and the applications of power electronics in power systems.

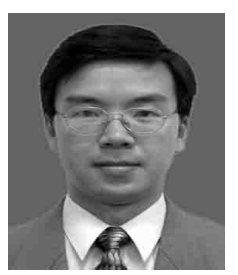

Jinjun Liu was born in Hunan Province, China in 1970. He received his B.S. and Ph.D. from Xi'an Jiaotong University (XJTU), China in 1992 and 1997, respectively. In 1998, he led the founding of the XJTU/Rockwell Automation Laboratory. From December 1999 until February 2002, he was with the Center for Power Electronics Systems at the Virginia Polytechnic Institute and State University, USA, as a Postdoctoral Research Scholar. He then came back to XJTU and in August of 2002 was promoted to Full Professor and Head of the Power Electronics and Renewable Energy Center. He is also serving as an Associate Dean in the School of Electrical Engineering at XJTU. He coauthored 3 books, published over 100 technical papers, and received several provincial or ministerial awards for scientific and career achievements. He was also a recipient of the 2006 Delta Scholar Award. His research interests include

power quality control, renewable energy generation, utility applications of power electronics, and the modeling and control of power electronic systems. Dr. Liu has served as the IEEE Power Electronics Society Region 10 Liaison for 3 years. He was actively involved in the organization of several power electronic international conferences, including PESC, APEC, IPEC in Japan, ICPE in Korea, and IPEMC in China, where he served as a Committee Member, a Co-Chair, or a Session Chair.

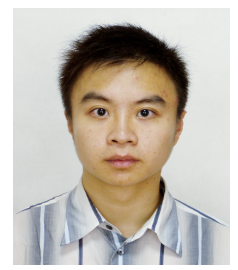

Jian Tang was born in Sichuan Province, China in 1982. He received his B.S from the University of Electronic Science and Technology of China, China in 2004. He is currently working toward his Ph.D. at the Huazhong University of Science and Technology, China His research interests include power quality control and the applications of power electronics in power systems.

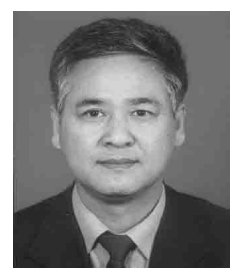

Zhaoan Wang was born in Shaanxi Province, China, in 1945. He received his B.S. and M.S. from Xi' an Jiaotong University, Xi' an, China, in 1970 and 1982, respectively, and his Ph.D. from Osaka University, Osaka, Japan, in 1989. From 1970 to 1979, he was an Engineer at Xi'an Rectifier Factory. He is now a Professor at $\mathrm{Xi}$ ' an Jiaotong University. He is engaged in research on power conversion systems, harmonics suppression, reactive power compensation and active power filters.

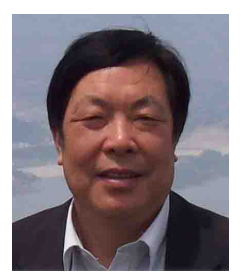

Yunping Zou was born in Hunan Province, China, in 1945. He received his B.S. from the Huazhong University of Science and Technology, Wuhan, China, in 1969. He has been a Full Professor at the Huazhong University of Science and Technology since 1994. His research interests include new power electronic circuits, devices and systems, as well as digital intelligent control technology and its basic application, signal detection, transform and processing. 